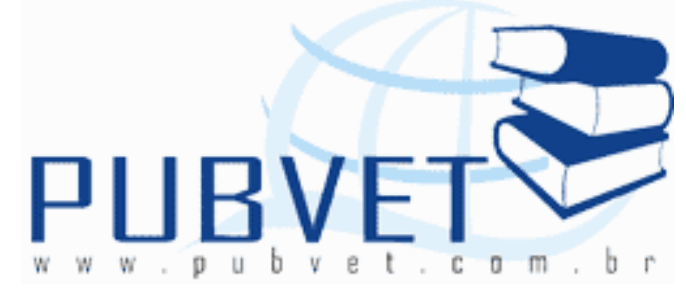

PUBVET, Publicações em Medicina Veterinária e Zootecnia.

\title{
Avaliação química de queijos Minas artesanais frescos e curados em Uberaba, MG
}

Nayara Cristina da Silva ${ }^{1}$, Risia May Matos Tunes ${ }^{2}$, Márcio Ferraz Cunha ${ }^{3}$

1 Aluna do curso de Nutrição-UNIUBE, Uberaba, MG, bolsista de iniciação científica da FAPEMIG, Campus Aeroporto.

${ }^{2}$ Aluna do curso de Nutrição-UNIUBE, Uberaba, MG, bolsista do programa de iniciação científica da UNIUBE, Campus Aeroporto.

3 Professor UNIUBE, Curso Nutrição, Campus Aeroporto, Bloco Z, Av. Nenê Sabino 1801, Uberaba MG, 38050-501. Email para correspondência: marcio.cunha@uniube.br

\section{Resumo}

O queijo Minas artesanal caracteriza-se pelo emprego do leite cru, cultura láctea natural, coalho e sal, e sua produção, tradicional, é uma importante fonte de renda para pequenos produtores do estado. Com a necessidade de obter informações que permitam enriquecer e aprofundar os conhecimentos do queijo Minas artesanal, especialmente em relação características químicas, foram coletadas 24 amostras de queijo Minas fresco e curado no município de Uberaba-MG para posterior avaliação de acidez, lactose, proteína, cloreto de sódio, umidade e sal na umidade, compostos nitrogenados da proteólise dos produtos e extensão e profundidade da maturação. Em média os resultados de acidez, lactose, proteína, nitrogênio total (NT), nitrogênio solúvel em pH 4,6 
(NS pH 4,6) e nitrogênio solúvel em TCA 12\% (NSTCA), cloreto de sódio, umidade, sal na umidade $(\mathrm{S} / \mathrm{U})$ para o queijo artesanal fresco e curado foram respectivamente: $1,03 / 1,10 \% ; 5,2 \mathrm{~g} / 100 \mathrm{gramas} / 4,6 \mathrm{~g} / 100 \mathrm{grama} ; 21,68 / 26,07$; $3,52 / 3,73 \% ; 0,30 / 0,47 \% ; 0,27 / 0,42 \% ; 1,43 \% / 1,98 \%, 47,4 / 32,81 \%, 2,86 / 6,3 \%$. A extensão (EM) e profundidade da maturação (PF) apresentaram valores iguais a $8,51 \%$ e $7,61 \%$ para queijos frescos e para queijos curados os valores foram 13,41\% e 11,49, respectivamente. Não houve diferença significativa entre os valores de acidez, lactose, proteína e NT, entretanto, houve diferença significativa para os parâmetros umidade, cloreto de sódio, S/U, NS pH4,6, NSTCA, EM e PF entre os queijos frescos e curados. Os valores médios de compostos nitrogenados, cloreto de sódio, $S / U$ e os índices IM e IP apresentaram maior valor nos queijos curados. O teor de umidade dos queijos curados foram inferiores em relação ao queijo fresco.

Palavras-chave: Qualidade, queijo, análise físico-química

\title{
Chemical evaluation of fresh and cured artisan Minas cheeses in Uberaba city, MG.
}

\begin{abstract}
The artisan Minas cheese is made by the use of raw milk, milk culture, natural rennet and salt, and its production, traditional, is a major source of income for small producers in the Minas State. With the need for information to enrich and deepen the knowledge of artisan Minas cheese, in particular chemical characteristics, was collected 24 samples of Minas cheese (12 fresh and 12 ripened cheese) in the city of Uberaba-MG for subsequent assessment of acidity, lactose, protein, sodium chloride, moisture and salt in moisture, nitrogen compounds of proteolysis of products and extension and depth of maturation. On average the results of acidity, lactose, protein, total nitrogen (NT), nitrogen soluble at pH $4.6(\mathrm{SN} \mathrm{pH} \mathrm{4.6)}$ and soluble nitrogen in TCA $12 \%$ (SNTCA), sodium chloride, moisture, salt in moisture $(S / M)$ for the artisanal cheese fresh and cured were respectively: 1.03/1.10\%; 5,2g/100grams/ 4,
\end{abstract}


6g/100grams； $21.68 / 26.07 \% ； \quad 3.52 / 3.73 \% ； \quad 0.30 / 0.47 \% ； \quad 0.27 / 0.42 \%$; $1.43 \% / 1.98 \%, 47.4 / 32.81 \%, 2.86 / 6.37 \%$. The extension (EM) and depth of maturation (DM) presented values equal to $8.51 \%$ and $7.61 \%$ for fresh cheeses and for cheeses ripened the values were $13.41 \%$ and 11.49 , respectively. There was no significant difference between the values of acidity, lactose, protein and NT, however, significant difference for the moisture parameters, sodium chloride, S/U, NS pH4 .6, NSTCA, and DM between fresh cheese and ripened. The average values of nitrogen compounds, sodium chloride, S/U, EM and DM indexes were greater value in ripened cheeses. The moisture content of ripened cheeses were lower than the fresh cheese.

Keywords: quality, cheese, physical-chemical analysis

\section{Introdução}

O Estado de Minas Gerais é o maior produtor de queijos do Brasil, com aproximadamente 215 mil toneladas anuais, sendo $70 \mathrm{mil}$ toneladas/ano, provenientes do queijo Minas artesanal, mantendo em atividade, aproximadamente 25 mil pequenos e médios produtores em de 500 dos 823 municípios do estado. Cerca de 10.000 produtores são das regiões: Serro, Alto Paranaíba, Serra da Canastra e Araxá, que produzem anualmente, 33.570 mil toneladas de queijo em 46 municípios, gerando 26.870 empregos diretos ${ }^{5,10,19}$.

O Instituto Estadual do Patrimônio Histórico e Artístico do Estado de Minas Gerais (IEPHA-MG) registrou o processo de fabricação do queijo Minas artesanal como Patrimônio Imaterial do Estado de Minas Gerais, ações como esta são de grande valia, pois resgatam a consciência sobre a importância destes queijos e valorizam o potencial econômico do patrimônio preservado, estimulando o desenvolvimento e o fortalecimento dessa atividade secular de agricultura familiar².

A produção de queijos exerce grande importância para a economia e identidade sócio-cultural do Estado, além de ser a principal atividade geradora 
de renda das famílias destas localidades. Acredita-se que o relevo montanhoso com pastagens naturais, as temperaturas mais baixas e a tradição das famílias produtoras determinam a fabricação dos queijos dessas regiões com aroma, cor, sabor e consistência singulares, sendo que, nessas regiões há uma predominância de microrganismos que dão características especiais aos queijo ${ }^{12}$.

O produto é elaborado com leite não-pasteurizado, utiliza um fermento endógeno, o soro coletado no dia posterior a fabricação do queijo, conhecido como "pingo", uma mistura de bactérias lácteas, entre as quais Lactococcus lactis e L. cremoris. O "pingo" é capaz de inibir o desenvolvimento de algumas bactérias indesejáveis e confere ao queijo características físico-químicas e sensoriais especificas ${ }^{3,4}$.

Atualmente existem mais de mil tipos de queijos em todo o mundo, cada um deles com características únicas em relação à forma, textura e sabor. A produção compreende de diversas técnicas que transformam grande parte dos componentes do leite num produto de fácil conservação, com menor quantidade de água, grande valor nutritivo e sabor agradável ${ }^{3}$.

Para se obter um queijo Minas artesanal de qualidade e para a proteção da saúde do consumidor é imprescindível que se associe: matéria-prima de qualidade, isto é, isenta de qualquer contaminação, e condições de processamento e maturação adequados.

Por se tratar de um produto popular, largamente consumido, os queijos artesanais vêm sendo alvo de monitoramentos constantes por parte dos órgãos de inspeção. Estes queijos tradicionais variam em suas características, por serem produzidos em locais variados e com diferentes tipos de processos, sem uma padronização na sua elaboração. Sendo assim, é comum que eles apresentarem características sensoriais diversificadas. Portanto, devido às inúmeras modificações que o queijo sofre durante seus processos de elaboração e maturação, o presente trabalho tem o objetivo de avaliar os 
teores de acidez, lactose e compostos nitrogenados em queijos artesanais da região e contribuir para sua padronização.

\section{MATERIAL e MÉTODOS}

A pesquisa coletou aleatoriamente vinte e quatro amostras de queijos Minas artesanal no comércio de Uberaba, MG, doze queijos frescos e doze queijos curados, assim identificados pelos varejistas, durante o ano de 2010. As amostras de queijos foram enviadas para análise química no laboratório de Análise de Alimentos da Universidade de Uberaba-MG (UNIUBE). Os queijos foram triturados e homogeneizados com auxílio de multiprocessador doméstico, acondicionados em frascos de plástico para as análises químicas.

\section{Determinação de acidez do queijo}

A determinação da acidez do queijo foi realizada utilizando uma solução padronizada de hidróxido de sódio $0,1 \mathrm{mols} / \mathrm{L}$ de acordo com as recomendações do Ministério da Agricultura ${ }^{7}$ e Silva et al. $^{26}$. Os resultados foram expressos em gramas de ácido lático por 100 gramas de produto.

\section{Determinação de Nitrogênio Total, Nitrogênio Solúvel em pH 4,6, Nitrogênio Solúvel em Ácido Tricloroacético.}

A determinação de nitrogênio total, das amostras de queijo foi realizada de acordo com o procedimento proposto por Silva et al. ${ }^{26}$. Quantidades apropriadas de queijos foram colocadas em solução de citrato de sódio 0,5mol/L e submeteu-se a mistura sob agitação durante 15 minutos. A suspensão obtida foi empregada para determinação do teor de nitrogênio total, nitrogênio solúvel em pH 4,6 e nitrogênio solúvel em ácido tricloroacético (TCA) $12 \%$.

O teor de nitrogênio total foi obtido após análise direta da quantidade de nitrogênio na suspensão pelo método de $\mathrm{Kjeldahl}^{26}$. A determinação de 
nitrogênio solúvel em pH 4,6 foi realizada após tratamento da suspensão com uma solução de ácido clorídrico $1,41 \mathrm{~mol} / \mathrm{L}$, e para determinação de nitrogênio solúvel em ácido tricloroacético (TCA) $12 \%$, após tratamento com a solução de TCA $24 \%$. Os filtrados obtidos após a filtração das suspensões foram empregados na determinação de nitrogênio pelo método de Kjeldahl ${ }^{26}$.

\section{Determinação da Extensão da Profundidade e Extensão da Maturação}

A determinação da extensão da maturação foi feita após a obtenção do nitrogênio solúvel em pH 4,6 (NS pH 4,6) e do nitrogênio total (NT). Assim calculou-se a razão entre o percentil de nitrogênio solúvel em pH 4,6 (NS pH 4,6 ) e do nitrogênio total (NT) e multiplicando-se o resultado por $100^{26}$.

A determinação da profundidade da maturação foi feita após a obtenção do nitrogênio solúvel em TCA $12 \%$ (NS TCA 12\%) e do nitrogênio total (NT). Assim calculou-se a razão entre o percentil de nitrogênio solúvel em TCA $12 \%$ (NS TCA $12 \%$ ) e do nitrogênio total (NT) e multiplicando-se o resultado por $100^{26}$.

\section{Determinação de Proteína}

A determinação de proteína foi feita pelo método de Kjeldahl de acordo com as recomendações de Silva et $\mathrm{al}^{26}$. O nitrogênio foi determinado utilizando uma solução padronizada de $\mathrm{HCl} 0,1 \mathrm{mols} / \mathrm{L}$ e o fator de conversão do teor de nitrogênio em proteína foi o valor 6,25.

\section{Determinação de Lactose}

A determinação da lactose foi realizada de acordo com o método de Acton $^{1}$, e as recomendações de Caruso e Oliveira ${ }^{9}$. Inicialmente elaborou-se uma curva padrão de lactose, coletando volumes variados de uma solução padrão de lactose (padrão analítico) com concentração de 20mg/100m1, volumes adequados da solução de fenol $5 \%$ e do ácido sulfúrico padrão analítico com $98 \%$ de pureza. Após 10 minutos de reação, foram realizadas 
medidas no espectrofotômetro na região do visível com comprimento de onda de 510nm, utilizando a água como "branco" da reação. Com os valores de absorbância obtidos no espectrofotômetro e a quantidade de lactose expresso em miligramas, realizou-se uma análise de regressão linear com auxílio do programa EXCEL da Microsoft.

A extração da lactose das amostras foi realizada após tratamento com uma solução de $\mathrm{NAOH}$ 0,5M e água destilada submetendo-as ao agitador magnético por cinco minutos, posteriormente a mistura foi submetida à ação da solução de sulfato de zinco $10 \%$. Após a filtração, coletou-se $2 \mathrm{~mL}$ do filtrado adicionando $0,8 \mathrm{~mL}$ da solução de fenol $5 \%$ e, em seguida, $5 \mathrm{~mL}$ de ácido sulfúrico concentrado. Posteriormente fez-se a leitura no espectrofotômetro, na região do visível, com comprimento de onda de $510 \mathrm{~nm}$, utilizando a água como "branco" da reação. O teor de lactose foi calculado com os valores de absorbância das amostras e com auxílio da curva padrão da lactose previamente elaborada.

\section{Determinação de umidade}

A umidade do queijo foi determinada utilizando o método de estufa. O produto foi colocado em uma estufa a temperatura de $102^{\circ} \mathrm{C}$ até que $\mathrm{O}$ material permanecesse com massa constante ${ }^{7}$.

\section{Determinação de cloreto de sódio (sal)}

A determinação de cloreto de sódio foi realizado a partir da incineração do produto a temperatura de 500 a $600^{\circ} \mathrm{C}$. A cinza obtida foi quantitativamente transferida para o erlenmeyer, e o cloreto de sódio foi quantificado empregando-se uma solução de nitrato de prata padronizada ${ }^{7}$.

\section{Determinação de sal na umidade ("salt-in-moisture")}

A determinação foi realizada empregando-se a seguinte fórmula: \% cloreto de sódio (sal) $\div \%$ umidade dos queijos $X 100^{15}$. 


\section{Análise estatística dos dados}

Os resultados da pesquisa foram submetidos à análise estatística descritiva (média, desvio padrão, coeficiente de variação) e análise de variância (ANOVA) com auxílio do programa Microsoft Office Excel versão 2007.

\section{RESULTADOS E DISCUSSÃO}

A Tabela 1 mostra os teores de cloreto de sódio (sal), umidade, teor de sal na umidade ("salt-in-moisture") em amostras de queijo Minas artesanal fresco e curado.

Tabela 1. Teores de umidade, cloreto de sódio (sal) em queijos Minas artesanais comercializados no município de Uberaba, MG.

\begin{tabular}{llcc}
\hline Amostras & Umidade (\%) & $\mathrm{NaCl}(\%)$ & Sal na umidade (\%) \\
Queijo Fresco & $47,24^{\mathrm{b}} \pm 3,92^{1}$ & $1,35^{\mathrm{a}} \pm 0,27$ & $2,86^{\mathrm{a}} \pm 0,58$ \\
Queijo Curado & $32,81^{\mathrm{a}} \pm 5,32$ & $1,98^{\mathrm{b}} \pm 0,71$ & $6,37^{\mathrm{b}} \pm 2,74$
\end{tabular}

1-Média土 desvio padrão; a,b:Letras diferentes na mesma coluna indicam houve diferença significativa $(p<0,05)$ entre as amostras de queijo.

A porcentagem de umidade foi maior nos queijos frescos $(p<0,05)$, igual a $47,24 \%$, enquanto os queijos curados os valores médios foram de $32,81 \%$. Os valores de umidades dos queijos Minas frescos e curados analisados variaram entre 41 a $52 \%$ e enquanto os queijos curados a variação foi maior entre 24 a 44\%, fato confirmado pelo maior valor de desvio padrão. 
De acordo com a legislação estabelecida pelo Instituto Mineiro de Agropecuária (IMA), o queijo Minas artesanal deve apresentar umidade inferior a $45,9 \%{ }^{14}$. Os resultados indicam que a maioria das amostras de queijos frescos analisados (67\% das amostras) estava fora do padrão estabelecido pela legislação. Todos os queijos maturados apresentaram teores de umidade de acordo com os critérios do IMA.

Os queijos Minas artesanais frescos seriam classificados como queijos de alta umidade de acordo com a legislação brasileira ${ }^{6}$, enquanto os queijos curados classificados como queijo de baixa umidade, com valores inferiores a $36 \%$ de umidade.

Machado et $\mathrm{al}^{17}$ obteve resultado para umidade em queijo artesanal entre $40,84 \%$ a 45,26\%, com média de 43,12\%, valores próximos ao observado no queijo fresco. Orsato et al. ${ }^{23}$ ao avaliarem queijos artesanais no estado do Rio Grande do Sul, conhecidos como queijos coloniais no Sul do país, verificaram que os teores de umidade dos queijos variaram entre 26,4 a $44,87 \%$.

O emprego do cloreto de sódio nos queijos tem importância por promover a sinérese do soro, com redução da umidade e atividade de água do produto, e desta maneira, afetar no desenvolvimento das bactérias láticas e patogênicas e enzimas proteolíticas importantes no processo de maturação 13,15 .

A média geral dos valores de cloreto de sódio para os queijos curados foram superiores $(p<0,05)$ aos queijos frescos, os respectivos valores médios foram de $1,98 \%$ e $1,35 \%$. O menor e maior valor de cloreto de sódio em queijos curados foram respectivamente 1,1 e 3,35\%, e para o queijo fresco, 0,9 e $1,8 \%$.

Silva ${ }^{25}$ encontrou um valor médio de cloreto de sódio igual a $1,95 \%$ para queijo Minas artesanal da região da Canastra, o queijo Minas curado da 
mesma região obteve uma média aproximada igual a 1,98\%. Nobrega et al. ${ }^{22}$ em seu estudo feito com queijos da mesma região, observou variação superior nos valores de cloreto de sódio dos produtos, entre 4 a $11 \%$.

O teor diversificado de cloretos no queijo se deve a variações da quantidade e a forma da adição do sal no processo de salga do queijo. Normalmente, a quantidade de sal utilizada é resultado da preferência e, ou dos saberes adquiridos ou transmitidos pelos produtores rurais com a arte de fabricar queijos ${ }^{8}$.

De acordo com Kindstedt ${ }^{15}$ a relação sal na água ("salt-in-moisture") é um indicador indireto da quantidade de água disponível presente nos queijos. Segundo o autor, quanto maior os valores desta relação menor a probabilidade das enzimas terem sua atividade plena e dos microrganismos se multiplicarem em razão de menor disponibilidade de água disponível.

Os queijos curados apresentaram valores superiores da relação sal na umidade em comparação dos queijos frescos $(p<0,05)$. O processo de maturação ou cura promove uma redução da atividade de água do queijo ${ }^{13}$.

A relação sal em umidade interfere no desenvolvimento da hidrólise da lactose e na hidratação das proteínas, fenômenos que tem influência no sabor, odor e textura dos queijos durante a sua maturação ou cura ${ }^{28}$. Pesquisas realizadas nos Estados Unidos indicam que os processos bioquímicos da maturação, devido à ação da renina, enzimas endógenas do leite e enzimas de bactérias láticas, devem ocorrer em níveis adequados da relação sal na umidade ${ }^{15,16}$. No Brasil não há pesquisas que estabeleçam valores ótimos deste parâmetro para maturação dos queijos, nos Estados Unidos recomendam teores de sal na umidade para queijo tipo Cheddar entre 4 a $6 \%{ }^{28}$.

A acidez titulável dos queijos, expressa em gramas de ácido lático em 100 gramas de produto, foi em média de 1,03 e 1,10, para os queijos frescos e curados, respectivamente (Figura 1). Embora, o valor médio de acidez, foi 
maior para os queijos curados, não houve diferença significativa do teor de acidez entre os queijos analisados $(p>0,05)$. O desvio padrão dos resultados de acidez dos queijos frescos foi de 0,10 e o observado nos queijos curados foi de 0,25 conforme ilustra a Figura 1.

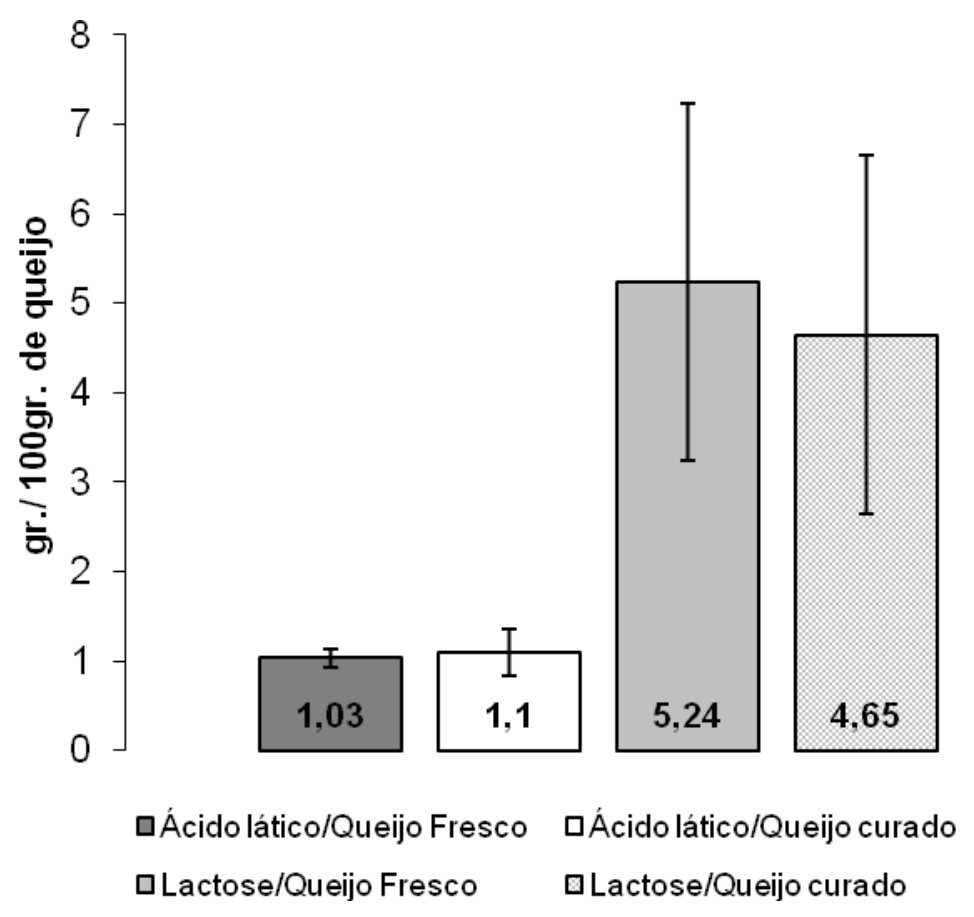

Figura 1.Valores de ácido lático e lactose em queijos artesanais fresco e curado adquiridos no mercado de Uberaba-MG.

Mata $^{20}$ observou uma acidez média de $1,08 \%$ para queijos Minas artesanal do Serro com 37 dias de maturação. Araújo ${ }^{2}$ ao realizar avaliações físico-químicas de queijos artesanais da região de Araxá encontrou valores médios de acidez de $0,77 \%$ não levando em conta o tempo de maturação. De acordo com Silva ${ }^{25}$ o teor médio de acidez de queijos artesanais da região da Canastra foi de $1,21 \%$ variando de $1,12 \%$ a $1,29 \%$.

As pesquisas já realizadas mostram uma grande variação nos valores de acidez dos queijos artesanais. O teor de ácido láctico pode sofrer influências 
da ação dos microrganismos presentes no leite, das variações na tecnologia de fabricação e utilização do "pingo". O aumento da acidez pode estar diretamente relacionado com o aumento da população dos microrganismos mesófilos, psicrotróficos e principalmente as bactérias lácticas, as quais são os principais agentes na transformação da lactose em ácido láctico.

A acidez tende a aumentar de acordo com o crescimento dos microorganismos, no transcorrer do período do armazenamento, beneficiando o produto por inibir a microbiota patogênica. Contudo a acidez excessiva pode prejudicar os aspectos sensoriais em queijos por produzir pronunciado sabor ácido descaracterizando o produto ${ }^{24}$.

O presente estudo encontrou valores bem variáveis para lactose, nota-se um teor de lactose maior para os queijos frescos (Figura1). Entretanto, não houve diferença significativa no teor de lactose entre os queijos analisados $(p>0,05)$. O valor médio de lactose para queijos frescos foi de $5,24 \mathrm{~g} / 100 \mathrm{~g}$, com desvio padrão de 2,02. O valor médio de lactose em queijos curados foi de $4,6 \mathrm{~g}$ lactose $(\mathrm{g} / 100 \mathrm{~g})$, com desvio padrão de 1,96 . Machado et al. ${ }^{17}$, encontrou valores médios de lactose para queijo Minas artesanal do Serro de $0,55 \mathrm{~g} / 100 \mathrm{~g}$.

Percebe-se que os valores encontrados foram bastante variados, o que pode ser explicado principalmente, pela falta de padronização dos queijos produzidos de forma artesanal. A quantidade de "pingo" e o tipo de microbiota contaminante, causam variações na intensidade e velocidade de fermentação da lactose e, conseqüentemente, no teor de lactose transformada em ácido láctico e na acidez desenvolvida.

A prensagem da massa também influencia no teor da lactose no queijo Minas, uma vez que esse componente pode ser eliminado em maior ou menor quantidade no soro, dependendo da força e tempo de prensagem da massa, causando diferenças no teor de lactose nos queijos de diferentes fazendas. 
Na Tabela 2 observa-se o efeito do tempo de maturação sobre os compostos nitrogenados do queijo. O valor médio de nitrogênio total expressos em porcentagem foi de 3,52\%, com desvio padrão de 0,35 para os queijos frescos, e de $3,73 \%$, com desvio padrão de 0,83 para os queijos curados.

Tabela 2. Valor médio de nitrogênio total, nitrogênio solúvel em $\mathrm{pH} 4,6$, nitrogênio solúvel em TCA e proteína de queijos artesanais fresco e curado adquiridos no mercado de Uberaba-MG.

\begin{tabular}{ccccc}
\hline $\begin{array}{c}\text { Queijos } \\
\text { Artesanais }\end{array}$ & $\begin{array}{c}\text { Nitrogênio } \\
\text { Total }(\%)\end{array}$ & $\begin{array}{c}\text { Nitrogênio } \\
\text { Solúvel em pH } \\
4,6(\%)\end{array}$ & $\begin{array}{c}\text { Nitrogênio } \\
\text { Solúvel em } \\
\text { TCA } 12 \% \\
(\%)\end{array}$ & $\begin{array}{c}\text { Proteína } \\
(\%)\end{array}$ \\
\hline Fresco & $3,52^{\mathrm{a}} \pm 0,35^{1}$ & $0,30^{\mathrm{a}} \pm 0,15$ & $0,27^{\mathrm{a}} \pm 0,09$ & $21,68^{\mathrm{a}} \pm 1,68$ \\
& & & \\
Curado & $3,73^{\mathrm{a}} \pm 0,83$ & $0,47^{\mathrm{b}} \pm 0,11$ & $0,42^{\mathrm{b}} \pm 0,12$ & $26,09^{\mathrm{a}} \pm 3,98$ \\
\hline Média \pm desvio padrão; a,b: Letras diferentes na mesma coluna indicam houve diferença \\
nnificativa $(\mathrm{p}<0,05)$ entre as amostras de queijo.
\end{tabular}

Nota-se que os queijos curados apresentam valores um pouco maiores, o que pode ser explicado pelo fato de que com a perda de umidade, há um aumento, na concentração dos sólidos totais e, por consequência, de compostos nitrogenados. Todavia o valor médio de nitrogênio total dos queijos curados, não foi significativamente superior em relação aos queijos frescos $(p>0,05)$.

Martins $^{19}$ encontrou uma relação semelhante, tendo valores de nitrogênio total menores em queijos frescos e maiores para queijos curados. O percentual médio de nitrogênio total para o queijo Serro curado com sete dias, foi próximo a 3,8\% e 4,2\% para o período da seca e da água, respectivamente. Machado et al. ${ }^{17}$ encontraram $2,94 \%$ de nitrogênio total no queijo Minas 
artesanal do Serro. Nos estudos de Sangaletti ${ }^{24}$, os percentuais médios de nitrogênio total foram entre $3,16 \%$ e 3,90\%.

Os valores médios, obtidos para nitrogênio solúvel em $\mathrm{pH} 4,6$, foi de $0,32 \%$, com desvio padrão de 0,15 para queijos frescos, e para os queijos curados a média foi $0,47 \%$, com desvio padrão de 0,11 (tabela 1 ). O valor médio do teor de nitrogênio solúvel em $\mathrm{pH} 4,6$ para os queijos curados foi superior aos queijos frescos $(p<0,05)$.

Martins $^{19}$ encontrou a mesma relação, no período da seca, para queijo Serro curado com sete dias obteve valores próximos a $0,4 \%$, sendo que durante o processo de cura houve um considerável aumento chegando no sexagésimo terceiro dia, a 0,8\%. No período das águas a variação foi menor, com sete dias, encontrou valores médios de nitrogênio solúvel pH 4,6 de 0,4\% e com sessenta e três dias já atingia aproximadamente $1 \%$.

Dores et al. ${ }^{11}$ também encontrou uma leve tendência de aumento nas médias de nitrogênio solúvel em pH 4,6 e nitrogênio solúvel em TCA $12 \%$ ao longo da maturação, independente do período de fabricação e da temperatura de armazenamento. Sangaletti ${ }^{24}$ encontrou nos seus estudos com queijos Minas frescal, variações de 0,23\% a 0,42\% de nitrogênio solúvel em pH 4,6, com maturação de 10 a 20 dias.

A temperatura ambiente favorece a proteólise primária representada pelos valores de nitrogênio solúvel em $\mathrm{pH} 4,6$, sendo formada pela quebra das proteínas durante a maturação dos queijos envolvendo primeiramente a conversão da caseína em grandes peptídeos, devido principalmente a ação residual da renina, coagulante normalmente empregada na fabricação dos queijos $^{11}$.

O valor médio de $0,27 \%$ de nitrogênio solúvel em TCA $12 \%$, com desvio padrão de 0,09 foi detectado em queijos frescos, e de 0,42\%, com desvio padrão de 0,12 para queijos curados (Tabela 1 ). O valor médio do teor de 
nitrogênio solúvel em TCA $12 \%$, para os queijos curados foi superior aos queijos frescos $(p<0,05)$.

Nos estudos de Martins ${ }^{19}$ os valores de nitrogênio solúvel em pH 4,6 e nitrogênio solúvel em TCA12\% aumentaram conforme o tempo de maturação, seja no período das águas ou da seca. O queijo da região do Serro, valores médios de nitrogênio solúvel em TCA $12 \%$, foram de 0,2\% (queijo maturado com sete dias) e 0,65\% (queijo maturado com sessenta e três dias), e 0,3\% (queijo maturado com sete dias) e 0,8\% (queijo maturado com sessenta e três dias) para a estação da seca e das águas respectivamente. Machado et al. ${ }^{17}$ observaram valores em queijo Minas artesanal do Serro igual a 0,27\% de nitrogênio solúvel em TCA $12 \%$.

O nitrogênio solúvel em pH 4,6 e o nitrogênio solúvel em TCA 12\% estão diretamente relacionados com a degradação de proteína (especialmente caseína) pela ação das enzimas do coalho e, ou por enzimas de microorganismos que formam peptídeos de alto peso molecular, peptídeos de cadeia curta e aminoácidos ${ }^{27}$.

Dores et al. ${ }^{11}$ explicam que as enzimas microbianas e aminopeptidases presentes no leite cru, são os principais responsáveis pela proteólise secundária, representada pelos valores de nitrogênio solúvel em TCA 12\%. A temperatura exerce uma influência importante sobre o desenvolvimento microbiano e a produção de suas enzimas, onde o seu ótimo depende de cada grupo microbiano.

O percentual médio de proteína dos queijos frescos não foi significativamente menor em relação aos queijos curados $(p>0,05)$. As medias encontradas para proteína foram de $21,68 \%$, com desvio padrão de 1,68 e $26,07 \%$, com desvio padrão de 3,98 para queijos frescos e curados, respectivamente. 
Silva $^{27}$ ao realizar avaliações físico-químicas de queijos Minas artesanal da Canastra encontrou valores de proteína total de $24,81 \%$ no período das águas e $23,07 \%$ no período da seca. Martins et al. ${ }^{18}$ observou que os queijos artesanais da região de Araxá apresentaram valores de proteína entre 21,83\% e $29,26 \%$, com média de $24,4 \%$. A porcentagem média de proteína de queijos Minas frescal do interior de São Paulo foi de $21,29 \%{ }^{24}$.

A proteína como é o componente que mais pode ser afetado pelo processo de fabricação, uma vez que, temperaturas baixas durante a coagulação do leite, perda de umidade, mexedura inadequada, são fatores que afetam o teor de proteína, o tempo de maturação também afetam o teor da mesma, queijos com menor grau de maturação, apresentam menores valores de proteína ${ }^{25}$.

Outro fator relevante para variação nos valores de proteína no queijo é que os produtores de queijo Minas Artesanal, não utilizam um sistema padronizado de alimentação animal, utilizando desde o tratamento extensivo, com o uso exclusivo de pastagens, até o tratamento semi-intensivo, com algum tipo de suplementação, como concentrados e cana de açúcar ${ }^{11}$.

A extensão da maturação ou o índice de proteólise é o resultado da ação proteolítica das enzimas do coalho e da plasmina sobre a caseína do leite, liberando peptídeos de alto peso molecular. Já a profundidade de maturação está relacionada, principalmente, com a atividade proteolítica do fermento láctico na maturação do queijo. Os microrganismos do fermento láctico produzem proteases capazes de hidrolisar peptídeos, produzindo assim compostos de baixo peso molecular e aminoácidos ${ }^{18,27}$. Estes índices são de grande importância na composição final e na qualidade do produto.

A proteólise é um fenômeno complexo que contribui para mudanças da textura, sabor, aroma do queijo. O desenvolvimento do sabor de queijos está ligado ao fracionamento da proteína com a presença principalmente de pequenos peptídios e aminoácidos hidrofóbicos. Durante a maturação a 
proteólise pode promover um amolecimento da textura no interior do queijo devido à hidrólise da caseína e pela redução da atividade de água ${ }^{21,27}$.

A Figura 2 e a análise estatística dos dados mostraram que o grau de extensão, assim como a profundidade da maturação foi superior em queijos curados em relação aos queijos frescos $(p<0,05)$. Conforme foi comentado anteriormente, a cura ou maturação do queijo permite ação de enzimas proteolíticas provenientes da microbiota contaminante, da ação residual do "pingo" e do coalho, e desta maneira, o aumento destes índices.

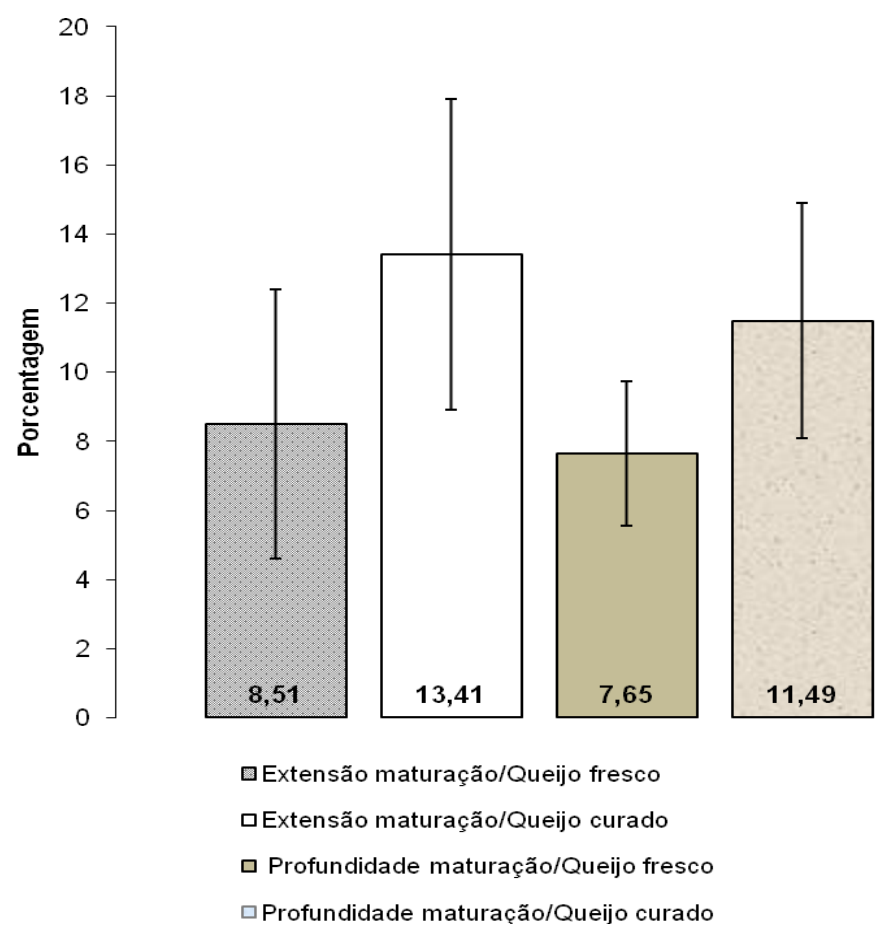

Figura 2. Valores da extensão de maturação e profundidade de maturação de queijos artesanais fresco e curado adquiridos no mercado de Uberaba-MG.

Os valores de 13,51 e 11,49\% para os níveis extensão e profundidade da maturação, respectivamente, para os queijos curados e de 8,51 e 7,65\% para os queijos frescos são similares aos observados na literatura para queijos artesanais mineiros. 
Silva ${ }^{25}$ em seus estudos com queijos Minas artesanal da Canastra encontrou níveis de extensão da maturação da ordem de 14,32\% no período das águas e no período da seca $10,36 \%$ e de profundidade de maturação de $11,87 \%$ no período das águas e no período da seca 7,18\% e altos coeficientes de variação ao analisar queijos Minas artesanal da Serra da Canastra.

\section{CONCLUSÃO}

Observaram-se variações nos parâmetros físico-químicos estudados nos queijos comercializados no mercado de Uberaba.

A maioria dos queijos frescos artesanais apresentou valores de umidade superiores ao indicado pela legislação mineira que estabelece critérios de qualidade para o produto.

A análise estatística dos dados observou que não houve diferença significativa nos valores de acidez, lactose, proteína e nitrogênio total, entretanto, houve diferença significativa para os parâmetros umidade, cloreto de sódio e sal na umidade, nitrogênio solúvel em pH 4,6, nitrogênio solúvel em TCA $12 \%$, extensão e profundidade da proteólise ao comparar os resultados dos queijos frescos e curados.

Pode-se verificar que o processo de maturação possibilita uma diferenciação das características físico-químicas do queijo Minas artesanal. Os valores médios de compostos nitrogenados, cloreto de sódio e sala na umidade apresentaram maior valor nos queijos curados, bem como, os índices de extensão de maturação e profundidade de maturação. Somente o teor de umidade dos queijos curados foram inferiores ao queijo fresco. As análises de umidade, cloreto de sódio e sal na umidade, extensão e profundidade da proteólise podem ser bons indicadores para diferenciação de queijos curados e frescos e na avaliação do grau de cura ou maturação do queijo. 
SILVA, N.C., TUNES, R.M.M. e CUNHA, M.F. Avaliação química de queijos Minas artesanais frescos e curados em Uberaba, MG. PUBVET, Londrina, V. 6, N. 16, Ed. 203, Art. 1358, 2012.

\section{AGRADECIMENTOS}

A Fundação de Amparo à Pesquisa do Estado de Minas Gerais (FAPEMIG) ao conceder a bolsa de iniciação científica para aluna Nayara Cristina da Silva.

\section{REFERÊNCIAS}

1. ACTON, G.H. The determination of lactose in cheese. The Austr. J. of Dairy Technol., p.111, 1977.

2. ARAUJO, R.A.B.M. Diagnóstico sócio-econômico, cultural e avaliação dos parâmetros físico-químicos e microbiológicos do queijo Minas artesanal da região de Araxá. 2004.121f. Dissertação (Mestrado em Ciência e Tecnologia de Alimentos). Universidade Federal de Viçosa, Viçosa, MG, 2004.

3. BORELLI, B.M. et al. Enteroxigenic Staphylococcus spp. and other microbial contaminants during production of Canastra cheese, Brazil. Braz. J. Micr., v.37, n. , 545-550, 2006.

4. BORELLI, B. M. et al. Qualidade microbiológica do queijo Minas artisanal maturado, produzido na região da Serra da Canastra, MG. Hig. Alim., v.24, nº 188/189, p.79-84, 2010.

5. BRANT, L.M.F.; FONSECA, L.M.; SILVA, M.C.C. Avaliação da qualidade microbiológica do queijo-de-minas artesanal do Serro-MG. Arq. Br. de Med. Vet. e Zootec., v.59, n.6, p.1570$1574,2007$.

6. BRASIL. Portaria n¹46 de 07 março de 1996. Ministério da Agricultura e do Abastecimento. Secretaria Nacional de Inspeção de Produtos de Origem Animal. Regulamentos técnicos de identidade e qualidade de produtos lácteos. Diário Oficial da União. Brasília, DF, março. 1996.

7. BRASIL. Instrução normativa $n^{\circ} .68$. Método oficial para análise físico-química de leite e derivados. Ministério da Agricultura, Pecuária e Abastecimento. Diário Oficial da União Brasília, DF, dez. 2006.

8. BEHMER; M L A. Tecnologia do Leite . $13^{a}$ ed. Revisada e atualizada - São Paulo, SP: Nobel, 1999.

9. CARUSO, E.C.; OLIVEIRA, A.J. de. Quantificação de lactose em queijos Minas frescal. Sci. Agric., Piracicaba, v. 56, n. 1, 1999. Disponível em: http://www.scielo.br/. Acesso em 27 Janeiro 2011

10. CRUZ, A.L. de M. et al. Qualidade microbiológica de queijo Minas artesanal comercializado em Montes Claros, MG. Hig. Alim., v.24, nº 190/191, p.136-39, 2010.

11. DORES, M.T. et al. Evolução da proteólise durante a maturação do queijo Minas artesanal da região da Serra da Canastra,MG. Anais do XXIV Congresso Nacional de Laticínios, $n^{\circ}$ 357, vol.62, p.446-450, 2007.

12. EMPRESA DE ASSISTÊNCIA TÉCNICA E EXTENSÃO RURAL DE MINAS GERAIS -MINAS GERAIS -EMATER-MG. Queijos tradicionais de Minas com mais qualidade. Rev. da EmaterMG, v 22,n. 80, p. 8-9, 2004. 
13. FOX, P.F. \& McSWEENEY, P.H.L. Dairy chemistry and biochemistry. London, UK: Blackie Academic \& Professional, 1998. p.379-435.

14. MINAS GERAIS. Governo do Estado de Minas Gerais. Decreto No 44.864. Altera o Regulamento da Lei n. 14.185, de 31 de janeiro de 2002, que dispõe sobre o processo de produção de Queijo Minas Artesanal.. Belo Horizonte - MG, 01/08/2008.

15. KINDSTEDT P. S. American Farmstead Cheese: The Complete Guide to Making and Selling Artisan Cheeses. $1^{\text {st }}$ Ed. White River Junction,VT , USA: Chelsea Green Publishing Company, 2005. 276p.

16. LAWRENCE, R. C.; HEAP, H.A.; GILLES, J. A controlled approach to cheese technology. J. Dairy Sci., v.67, n.8, p.1632-1645, 1984.

17. MACHADO, E.C. et al. Características físico-químicas e sensoriais do queijo Minas artesanal produzido na região do Serro, Minas Gerais. Ciênc. e Tecnol. de Alim., v. 24, n.4, 516-521, 2004.

18. MARTINS, J.M. et al. Características físico-químicas dos queijos Minas artesanais produzidos na região de Araxá. Anais do XXI Congresso Nacional de Laticínios, $\mathrm{n}^{\circ} 339$, vol.59, p.317-319, 2004.

19. MARTINS, J.M. Características físico-químicas e microbiológicas durante a maturação do queijo Minas artesanal da região do Serro. 2006.158f. Tese (Doutorado em Ciência e Tecnologia de Alimentos). Universidade Federal de Viçosa, Viçosa, MG, 2006.

20. MATA, G.M.S.C. Comparação de métodos para pesquisa de Salmonella sp. e Listeria sp.e avaliação microbiana e físico-química em queijo Minas Artesanal. 2009. 89f. Dissertação (Pós graduação em Microbiologia Agrícola). Universidade Federal de Viçosa, Viçosa, MG, 2009.

21. McSWEENEY, P.L.H. Biochemistry of cheese ripening. Int. J. Dairy. Technol., v. 57, n. 2/3, p.127-143, 2004.

22. NOBREGA, J.E. da et al. Perfil do fermento endógeno utlizado na produção do queijo Minas artesanal na Serra da Canastra, Minas Gerais. Anais do XXIII Congresso Nacional de Laticínios, $\mathrm{n}^{\circ}$ 351, vol.61, p.427-429, 2006.

23. ORSATO, J. et al. Avaliação microbiológica e caracterização físico-química, pelo método do Near Infrared Reflectance (NIRS), de queijos coloniais comercializados na região de Passo Fundo, RS. Hig. Alim., v.24, nº 183, p.127-132, 2010.

24. SANGALETTI, N. Estudo da vida útil do queijo Minas frescal disponível no mercado. 2007. 81f. Dissertação (Mestrado em Ciência e Tecnologia de Alimentos). Universidade de São Paulo Escola Superior de Agricultura "Luiz de Queiroz", Piracicaba, 2007. Disponível em: < http://www.teses.usp.br/teses/. Acesso em: 21 dezembro. 2010.

25. SILVA, J.G. Características físicas, físico-químicas e sensoriais do queijo Minas artesanal da Canastra. 2007. 210f. Dissertação (Mestrado em Ciência de Alimentos). Universidade Federal de Lavras, Lavras, MG, 2007.

26. SILVA, P. H. F. et al. Físico- química de leite e derivados- Métodos analíticos. Juiz de Fora, MG: Oficina de Impressão Gráfica e Editora LTDA. ed.1a, p. 190, 1997.

27. SOUSA, M.J.; ARDO, Y.; McSWEENEY, P.L.H. Advances in study of proteolysis during cheese ripening. Int. Dairy. J., v.11, p.327-345, 2001. 
28. UPRETI, P ; METZGER, L.E. Influence of calcium and phosphorus, lactose, and salt-tomoisture ratio on Cheddar cheese quality: Manufacture and composition J. Dairy Sci., v.89, n.2, p.420-428, 2006. 